\title{
"Difundir cultura e ilustración". Las bibliotecas populares en la trama de la sociabilidad de las poblaciones pampeanas, 1905-1955
}

Doi: $10.25100 /$ hye.v14i51.6985

Artículo recibido: 24-12-2017 | Artículo aceptado: 04-07-2018

\section{María de los Ángeles Lanzillotta}

Profesora e investigadora de la Universidad Nacional de La Pampa (Santa Rosa, Argentina). Magíster en estudios sociales y culturales. Ha seguido una línea de investigación que focaliza en el estudio de los intelectuales y productores culturales en el Territorio Nacional de la Pampa desde un enfoque centrado en los lineamientos sociales del proceso de emergencia de los grupos y de la producción intelectual en sociedades de reciente reconfiguración.

Correo electrónico: marialanzillotta@hotmail.es

\section{Micaela Oviedo}

Estudiante de la Carrera de Historia de la Facultad de Ciencias Humanas, Universidad de La Pampa (Santa Rosa, Argentina). Desarrolla la investigación en el marco de una de Beca Estímulo a las Vocaciones Científicas otorgada por el Consejo Interuniversitario Nacional.

Correo electrónico: micaelaoviedo993@gmail.com

Forma de citar este artículo: Lanzillotta, María de los Ángeles y Micaela Oviedo. “Difundir cultura e ilustración". Las bibliotecas populares en la trama de la sociabilidad de las poblaciones pampeanas, 1905-1955”. Historia y Espacio, vol. 14, nº 51 (2018): 75-107. Doi: 10.25100/hye.v14i51.6985.

Artículo Tipo 1: de investigación. 


\section{"Difundir cultura e ilustración". Las bibliotecas populares en la trama de la sociabilidad de las poblaciones pampeanas, 1905-1955}

Resumen : Las bibliotecas populares constituyeron espacios significativos en la dinámica de la vida social y cultural en algunas ciudades del "interior" argentino a principios del siglo XX. En estos lugares, las bibliotecas conformaron un espacio clave del proceso de modernización e integración social de amplios sectores en las poblaciones emergentes de la región pampeana. Para indagar las características del proceso de creación de bibliotecas populares y la ampliación del público lector en sociedades nuevas, de reconfiguración reciente, esta investigación se propone, en primer lugar, elaborar una cartografía de la creación de las bibliotecas populares en los Territorios Nacionales; y en segundo lugar, analizar, en el marco de la dinámica social de una biblioteca, la Biblioteca Popular Florentino Ameghino de la localidad de Guatraché, los cambios y las continuidades evidenciados en los perfiles y las preferencias de sus lectores y lectoras.

Palabras clave: Bibliotecas populares, sociabilidad, instituciones, lecturas.

\section{"Spreading culture and illustration". Popular libraries within the frame of sociability of the Pampas populations, 1905-1955}

Abstract: Popular libraries constituted significant spaces in the dynamics of social and cultural life in some cities of the Argentina's hinterland at the beginning of the 20th century. In these places, libraries formed a key space for the process of modernization and social integration of large sectors in the emerging populations of the Pampas region. In order to investigate the characteristics of the process of creation of popular libraries and the expansion of the reading public in new societies of recent reconfiguration, this research proposes, first of all, to create a cartography of the creation of popular libraries in National Territories and, secondly, it explores changes and continuities in profiles and preferences of its readers, within the context of the social dynamics of a particular library, the Florentino Ameghino Popular Library in Guatrache town.

Keywords: Popular libraries, sociability, institutions, readings. 


\author{
María de los Ángeles Lanzillotta \\ Micaela Oviedo
}

"Difundir cultura e ilustración". Las

bibliotecas populares en la trama de la 1905-1955

\title{
Introducción
}

En el Territorio Nacional de la Pampa la creación de las bibliotecas populares se inició a principios del siglo XX de forma paralela al crecimiento de numerosos pueblos y ciudades pequeñas, en el contexto de una sociedad de repoblamiento reciente que se vio atravesada por procesos de configuración política y de diferenciación social ${ }^{1}$. En ese entonces, la sociedad civil fue delineando el entramado de diferentes instituciones a partir de los intereses y las necesidades de los distintos sectores, en el marco de una participación política formal restringida a la elección de representantes en el ámbito municipal ${ }^{2}$.

1 Leticia Prislei utiliza esa categoría en sus estudios para los territorios de Neuquén y Río Negro, en alusión a la emergencia de pueblos y ciudades y la gestación de un proceso de diferenciación interna de la sociedad. Leticia Prislei. "Imaginar la Nación, modelar el desierto: los '20 en tierras del Neuquén”. En Pasiones sureñas. Prensa y cultura política en la Frontera Norpatagónica (1884-1946), editado por Leticia Prislei. (Buenos Aires: Prometeo, 2001), 80.

2 La ley 1532 organizó los territorios recientemente incorporados al Estado Nacional en 9 Territorios Nacionales: La Pampa, Neuquén, Río Negro, Chubut, Santa Cruz, Tierra del Fuego, Misiones, Formosa y Chaco. 
En ese ámbito particular consideramos el estudio de las bibliotecas populares ${ }^{3}$, entidades que requieren un análisis transversal entre diferentes perspectivas, puesto que actuaban como bisagras entre el Estado y los distintos actores y organizaciones de la sociedad civil ${ }^{4}$. Ello pone de manifiesto la necesidad de integrar diversos andamiajes teóricos para complejizar el análisis, enfoques que provienen de la historia social, la historia cultural, la historia política. Algunos estudios precedentes han focalizado el análisis de las bibliotecas desde distintos lineamientos teóricos y metodológicos. A partir una orientación centrada en la historia social, Luis Alberto Romero y Leandro Gutiérrez ${ }^{5}$ indagaron en la emergencia de las bibliotecas barriales en Buenos Aires, e identificaron el período de auge de este fenómeno al lapso comprendido entre 1920 y 1945. Sus investigaciones enfatizan en la importancia de estas entidades en la formación educativa de sectores de la población no alcanzados por el sistema educativo estatal y en la configuración de la identidad de los sectores populares de Buenos Aires, que se fueron transformando en agentes más proclives a la integración, al fomentismo y al reformismo social. En la misma línea, se encuentran los estudios de Dora Barrancos, que han destacado el lugar ocupado por las bibliotecas vinculadas con la Sociedad Luz $\mathrm{z}^{6}$ y los trabajos de Ricardo Pasolini ${ }^{7}$ y de Nicolás Quiroga ${ }^{8}$ acerca de las lecturas de los sectores populares y bibliotecas de Tandil y Mar del Plata. Estudios más recientes -como

3 Las bibliotecas populares son entidades sin fines de lucro que se sostienen con una cuota asociativa y una de las condiciones para recibir el apoyo oficial era el principio explícito de apoliticidad en sus estatutos.

4 Javier Planas, Libros, lectores y sociabilidades de lectura. Una historia de los orígenes de las bibliotecas populares en la Argentina. (Buenos Aires: Ampersand, 2017), 21.

5 Al respecto véase Luis Alberto Romero. "Los sectores populares en la ciudades latinoamericanas del siglo XIX: la cuestión de la identidad”, Desarrollo Económico Revista de Ciencias Sociales, 27, nº 106 (1987): 201-222; Luis Alberto Romero y Leandro Gutiérrez, “Sociedades barriales, bibliotecas populares y cultura de los sectores populares: Buenos Aires, 19201945”, Desarrollo Económico Revista de Ciencias Sociales, 29, nº 113, (1989): 35-62.

6 Dora Barrancos, La escena iluminada. Ciencias para trabajadores 1890-1930. (Buenos Aires, Plus Ultra, 1996).

7 Ricardo Pasolini. "Entre la evasión y el humanismo. Lecturas, lectores y cultura de los sectores populares: La Biblioteca Juan B. Justo de Tandil, 1928-1945”. Anuario del IEHS, 12 (1997): 373-401.

8 Nicolás Quiroga, “Lectura y política. Los lectores de la Biblioteca Popular Juventud Moderna de Mar del Plata (fines de los años treinta y principios de los cuarenta)". Anuario del IESH, 18 (2003): 449-474. 
los de Flavia Fiorucci ${ }^{9}$ - han centrado su análisis en las políticas culturales del peronismo en relación con la Comisión Protectora de Bibliotecas Populares (CPBP) y se cuenta también con los las investigaciones de Javier Guiamet y Federico Martocci ${ }^{10}$ sobre las políticas culturales del Partido socialista. A estos trabajos hay que sumarle aportes provenientes del campo de la historia de la lectura y la bibliotecología; en especial, se hace necesario mencionar las contribuciones de Alejandro Parada ${ }^{11}$ y Javier Planas ${ }^{12}$.

En este estudio analizaremos la expansión de las bibliotecas populares en espacios menos urbanizados, con una dinámica política y social diferenciada del resto de las provincias argentinas ${ }^{13}$. En este marco, cobra relevancia el análisis de dichas instituciones y sus prácticas en los contornos de una sociedad de reciente conformación, dotada de una organización estatal embrionaria ${ }^{14}$ que favoreció las condiciones de emergencia de los poderes municipales a nivel de cada localidad, en el contexto de una sociedad dotada de un sistema educativo insuficiente, las altas tasas de analfabetismo y de deserción escolar ${ }^{15}$. Todas

9 Flavia Fiorucci, "La cultura, el libro y la lectura bajo el peronismo: el caso de la Comisión de Bibliotecas Populares”. Desarrollo Económico-Revista De Ciencias Sociales, 48, Nº 192 Enero-Marzo (2009): 543-556.

${ }^{10}$ Para las políticas culturales del Partido Socialista ver Javier Guiamet “Tentaciones y prevenciones frente a la cultura de masas. Los socialistas argentinos en el periodo de entreguerras". Tesis de Doctorado en Historia. Universidad Nacional de La Plata. Defendida en septiembre de 2017. Para el caso de la biblioteca del partido Socialista de Santa Rosa ver Federico Martocci, La política cultural del Partido Socialista en el Territorio Nacional de La Pampa: dispositivos y prácticas de intervención de sus dirigentes e intelectuales, 1913-1939 (Santa Rosa, EdULPam, 2015).

${ }^{11}$ Alejandro Parada, El dédalo y su ovillo ensayos sobre la palpitante cultura impresa en la Argentina, (La Plata: Universidad Nacional de La Plata, 2012).

12 Javier Planas, Libros, lectores y sociabilidades de lectura, 2017.

${ }^{13}$ A nivel provincial se cuenta con estudios precedentes sobre las bibliotecas de las localidades, para Guatraché ver María Lanzillotta,"De lectores y anaqueles: Bibliotecas Populares”. En Esta Antigua tierra que somos Guatraché 1908-2008, editado por Ana María Rodríguez, Marisa Moroni y Oscar Folmer (Buenos Aires, Miño y Dávila, 2008), 329-338.

${ }^{14}$ María Silvia Di Liscia, "Dificultades y desvelos de un estado interventor. Instituciones, salud y sociedad en El interior argentino. La Pampa, 1930-1946”, Anuario IEHS, vol. №22, (2007): 93-123.

15 En el Territorio de la Pampa el analfabetismo alcanzaba el 36,1\% de los adultos en 1920 [Juan Carlos Tedesco y Alejandra Cardini, "Educación y sociedad, proyectos educativos”. En Una historia social del siglo XX, T.II compilado por Susana Torrado (Buenos Aires: Edhasa, 2007), 462] y al 40\% de los niños en edad escolar no concurrían a la escuela en 1931. María 
esas coordenadas incentivaron la gestación de otros mecanismos informales y alternativos al interior de la sociedad civil ${ }^{16}$, al tiempo que propiciaron el crecimiento de un conjunto de prácticas vecinalistas ${ }^{17} \mathrm{y}$ de redes de militancia política, consideradas sustanciales para cubrir las crecientes necesidades que tenían los pobladores de los incipientes centros urbanos.

Entre los distintos tipos de asociaciones creados por la sociedad civil, las bibliotecas populares tuvieron una relevancia cuantitativa y cualitativa. Es por ello que en la primera parte de este trabajo nos interrogaremos acerca de la dinámica social del proceso de surgimiento de las bibliotecas populares en el Territorio Nacional de la Pampa con el objeto de esbozar coordenadas que sirvan de marco para examinar los ritmos y alcances del proceso de fundación de las bibliotecas en el ámbito de pequeñas y medianas localidades. En la segunda parte del trabajo analizaremos el funcionamiento de una de esas bibliotecas, el juego de escala que articula el microanálisis con el macro nos permitirá identificar particularidades de la trama de la sociabilidad cultural local, al tiempo que nos acercará al reconocimiento de ciertas estrategias y prácticas relacionadas con la difusión de la lectura en ciudades y círculos de población más reducida.

\section{El proceso de emergencia de las Bibliotecas Populares}

La cronología de las fundaciones en el Territorio Nacional de La Pampa nos induce a esbozar una primera periodización. En ese espacio, se creó en 1905 la biblioteca territoriana más antigua, la Biblioteca Popular "Bartolomé Mitre”, de Victorica. El maestro socialista Cristóbal Cleto Rodríguez Kessy explicaba en una de las notas de prensa ese proceso:

La biblioteca era una "universidad", adonde se prolongaba el sexto grado de la escuela pública de entonces. Félix Romero -maestro sin título-, hizo el

José Billorou y Laura Sánchez, "Escuelas, maestros, inspectores. La dinámica del sistema educativo en el Territorio de la Pampa, 1880-1930”. En Historia de La Pampa: sociedad, política yeconomía. De los poblamientos iniciales hastala provincialización, editado por Claudia Salomón Tarquini y Andrea Lluch (Santa Rosa: EdUNLPam, 2014), 431.

${ }^{16}$ Ernesto Boholavsky, "Sobre los límites del control social. Estado, historia y política en la periferia argentina (1890-1930). En Instituciones y formas de construcción social en América Latina, 1840-1940, una revisión, editado por María Silvia Di Liscia y Ernesto Boholavsky (Buenos Aires: Prometeo, 2005), 59.

${ }^{17}$ Fabio Alonso, El peronismo en La Pampa. Conformación partidaria y construcción estatal 19451955. (Rosario: Prohistoria, 2015), 35. 
sexto grado bajo la guía de aquel maestro francés, Miguel de Fougéres, en la Escuela $\mathrm{N}^{\mathrm{o}} 7$ de Victorica, y prolongó la enseñanza del aula en la biblioteca Bartolomé Mitre. Fundada por el (sic) mismo Félix Romero, se inauguró el 04 de junio de $1905 .^{18}$

Más allá de este relato, las diversas circunstancias que incentivaron la creación de bibliotecas en La Pampa en los albores del siglo no eran excepcionales y, en cierta forma, respondían a un movimiento de vasto alcance, vinculado con el asociacionismo, la creciente participación de la sociedad civil ${ }^{19}$ y con el proceso de expansión de las Bibliotecas Populares en Argentina entre fines del siglo XIX y primeras cuatro décadas del siglo $\mathrm{XX}^{20}$, fenómeno ampliamente perceptible por lo menos en la región central del país. Sin embargo, el espacio que nos ocupa tuvo -por razones que responden a su propia dinámica de composición social-, algunas diferencias con esa periodización general. La creación de bibliotecas en el Territorio mostró su etapa prolífica entre $1910 \mathrm{y}$ mediados de la década del treinta, lapso en el que se produjo la fundación de la mayor parte de las bibliotecas en los pueblos del Centro-Este de La Pampa ${ }^{21}$. Gran parte de las bibliotecas estaban ubicadas en esa franja de mayor densidad poblacional y comunicacional, espacio conformado por una ramificación de pequeños centros urbanos conectados por el ferrocarril (Figura 1).

${ }^{18}$ Cristóbal Cleto Rodríguez Kessy,Dela antigua escuelayotras historias. (Buenos Aires: Imprenta de los Buenos Ayres, 2006), 23.

19 Sandra Carli, "Infancia y Sociedad. La mediación de asociaciones, centros y sociedades populares de educación”. En Historia de la Educación en la Argentina. Sociedad civil y Estado en los orígenes del sistema educativo argentino dirigido por Adriana Puiggrós (Buenos Aires, Galerna, 1998),13-46.

20 Según Susana Leloutre en 1910 existían 191 bibliotecas en todo el país y en 1925 se contabilizaron 1012. Susana Leloutre, “Las bibliotecas populares entre los años 1998-2003.”Tesis de licenciatura, Universidad Nacional de La Plata, 2010, 35.

${ }^{21}$ Para el año 1914 el Territorio contaba con dos ciudades medianas y 26 localidades más pequeñas que iban de 800 a 2500 habitantes. El Territorio Nacional tenía entonces una población de 101.338 habitantes. Las ciudades más grandes eran Santa Rosa, con 5487 habitantes en 1912 y 12996, en 1942; en tanto que General Pico contaba con una población de 6044 y 10846 personas respectivamente. Ver María Silvia Di Liscia y Andrea Lluch "La población pampeana y sus transformaciones”. En Historia de La Pampa, sociedad política y economía, desde los poblamientos iniciales hasta la provincialización (ca.8000 ap. a 1952), editado por Andrea Lluch y Claudia Salomón Tarquini,Rosario, Ediciones del Boulevard, 2008, 113-123. 
"Difundir cultura e ilustración". Las bibliotecas populares en la trama de la sociabilidad de las ...

María de los Ángeles Lanzillotta - Micaela Oviedo

Figura 1. Bibliotecas reconocidas por la Comisión Protectora de Bibliotecas Populares (CPBP) en los Territorios Nacionales de la Pampa, Chaco y Río Negro

\begin{tabular}{|c|c|c|c|c|c|c|}
\hline & & $\begin{array}{l}\text { Territorio } \\
\text { Nacional de } \\
\text { La Pampa }\end{array}$ & & $\begin{array}{l}\text { Territorio } \\
\text { Nacional } \\
\text { del Chaco }\end{array}$ & & $\begin{array}{l}\text { Territorio } \\
\text { Rio Negro }\end{array}$ \\
\hline & $\begin{array}{l}\text { B. } \\
\text { Escolares }\end{array}$ & Total & $\begin{array}{l}\text { B. } \\
\text { Escolares }\end{array}$ & Total & $\begin{array}{l}\text { B. } \\
\text { Escolares }\end{array}$ & Total \\
\hline 1929 & 15 & 41 & 6 & 13 & 4 & 12 \\
\hline 1935 & 20 & 48 & 6 & 13 & 6 & 16 \\
\hline 1938 & 17 & 48 & 7 & 14 & 6 & 16 \\
\hline 1941 & 17 & 50 & 6 & 13 & 6 & 16 \\
\hline 1954 & 19 & 55 & 16 & 28 & 2 & 18 \\
\hline 1966 & 16 & 55 & 11 & 21 & 4 & 20 \\
\hline
\end{tabular}

Fuente: elaboración propia con base a estadísticas publicadas por la CPBP: Nómina de las Bibliotecas Populares que fomenta la Comisión protectora de Bibliotecas Populares, Buenos Aires 1929, Nómina de las Bibliotecas Protegidas, Buenos Aires, 1935; Nómina de las Bibliotecas Protegidas, Buenos Aires, 1938; Nómina de las Bibliotecas Populares Protegidas 1941; Guía de las Bibliotecas Argentinas. T II Buenos Aires, 1955; Nómina de las Bibliotecas Protegidas, Buenos Aires, 1966.

Esas cifras dan cuenta solo de los establecimientos reconocidos como bibliotecas populares por la Comisión Nacional -sabemos que no todas se pueden considerar bibliotecas en actividad; además, las estadísticas incluyen a bibliotecas populares municipales y escolares. Al comparar la situación de La Pampa en relación con otros Territorios Nacionales, las distancias que se evidencian son notables; según estos datos, el este pampeano se asemejaba más, en cuanto a la cantidad de bibliotecas, a las provincias de la región pampeana y ello representaba una cartografía diferencial en relación con otras jurisdicciones, indicio que debe ser analizado en el marco de una densidad poblacional y social diferenciada.

Ese contraste entre La Pampa y los demás Territorios puede atribuirse a factores diversos. Como ya se ha advertido, para el caso de Victorica, la fundación de algunas bibliotecas estaba en relación directa con la presencia de los maestros, de sus tempranas agrupaciones profesionales y sus prácticas intelectuales, que incentivaban la participación más allá del sistema educativo formal, sin desconocer la formación de las nuevas agrupaciones gremiales, políticas e intelectuales. Sin embargo, todas estas estrategias de distintos agentes no fueron individuales, tuvieron como plafón demandas sociales vinculadas con la difusión de prácticas de lectura y escritura entre sectores 
amplios de una población integrada por extranjeros recién arribados o bien nativos, actores sociales que detentaban una escritura incipiente y, en algunos casos, hasta desconocían el idioma, pues utilizaban distintos dialectos ${ }^{22}$.

En los centros urbanos específicos, como Santa Rosa y General Pico, Lonquimay, Macachín y General San Martín se crearon bibliotecas en las comunas. No contamos con estudios para todos los casos, pero en las indagaciones sobre la organización de las primeras bibliotecas de la capital pampeana, se ha detectado la incidencia de contactos y experiencias previas de otras organizadas hacia finales del siglo en las provincias. Algunas de esas instituciones sirvieron de modélicas, aunque la normativa debió adaptarse a los contornos de la nueva sociabilidad:

[...] fuimos a la Municipalidad donde se celebraba la asamblea de la infortunada Biblioteca Alberdi. Estaban muchos muchachos, hacían correr una lista presidida por Costa y donde Font era secretario y yo tesorero. Mientras allí esperábamos fueron llegando maestras quienes se instalaron en el salón. Estaban Marcos Molas y Alfredo Torres al frente, como secretario lo pusieron a Dávila[...] Después comenzó la lectura de unos reglamentos, según dijo los había copiado de la Biblioteca Alberdi de Tucumán. Font, Bianchi y yo tomamos la palabra para lograr que los socios activos fueran cuanto queriéndolo ser, tuvieran más de 14 años. El buen Torres los quería mayores de edad. Además hicimos bajar la cuota a cincuenta centavos en vez de un peso propuesto por el proyecto. ${ }^{23}$

A excepción de esos casos más tempranos, las bibliotecas en el Territorio tuvieron un accionar destacado en las décadas de 1920 y 1930, ello estaba en consonancia con algunos cambios generales en las prácticas políticas y

22 Según el Censo Nacional de 1914, la población extranjera alcanzaba a un 36,4\% y se concentraba en el centro y este del Territorio Nacional de la Pampa. República Argentina, Tercer Censo Nacional, 1914, 262-372.

23 “Yo", Pedro Fernández Acevedo, miércoles 05-09-18. El diario personal del maestro y abogado Fernández Acevedo. (Inédito). Repositorio de Esmilda Fernández Acevedo. Santa Rosa, La Pampa. 
culturales. El socialismo ${ }^{24}$ y el radicalismo ${ }^{25}$ tuvieron un crecimiento importante en esos años. De manera simultánea, los militantes anarquistas también crearon sus bibliotecas, periódicos y centros culturales en las localidades del nordeste territoriano ${ }^{26}$. Esas tres agrupaciones organizaron bibliotecas en las distintas localidades. Entre socialistas y anarquistas, la creación de bibliotecas y periódicos era una práctica corriente de la militancia. En el caso del radicalismo, los estudios de Romero para Buenos Aires postulan que si bien existieron bibliotecas dentro de los locales del partido, siempre fueron esporádicas y se gestaron ante la inminencia de las elecciones ${ }^{27}$. En el territorio pampeano, las bibliotecas radicales se organizaron en la década de 1930, con posterioridad a la emergencia de la mayoría de los centros anarquistas y socialistas y fueron emprendimientos ubicados en los núcleos urbanos de Santa Rosa y General $\mathrm{Pico}^{28}$. A pesar de los orígenes diversos, cada una de las bibliotecas daba cuenta

${ }^{24}$ El primer centro socialista del Territorio surgió en 1913. Un año después, llegaron a ocupar dos bancas en el Concejo santarroseño. El período de mayor expansión del socialismo se produjo en la segunda mitad de la década de 1920, cuando llegaron a contar con 13 centros en distintas localidades pampeanas y tuvieron a su cargo la conducción de las comunas de las ciudades de Santa Rosa y General Pico. Luciano Valencia, "El Partido Socialista”. En Historia de La Pampa, sociedad política y economía, desde los poblamientos iniciales hasta la provincialización (ca.8000 ap.a 1952), editado por Andrea Lluch y Claudia Salomón Tarquini (Rosario: Ediciones del Boulevard, 2008), 417-423.

${ }^{25}$ El año 1916 fue de intensa actividad política para los radicales pampeanos. El primer paso estuvo dado por la organización de una estructura partidaria, que comenzó con la creación de un Comité Central Departamental en el mes de mayo, al que luego se le sumaron los comités de Macachín, Santa Rosa, Castex y General Pico. María Esther Folco y María Lanzillotta "El Radicalismo". En Historia de La Pampa, sociedad política y economía, desde los poblamientos iniciales hasta la provincialización (ca.800 ap. a 1952), editado por Andrea Lluch y Claudia Salomón Tarquini (Rosario: Ediciones del Boulevard, 2008), 397.

${ }^{26}$ El espacio en el que se desarrollaron la mayor parte de las actividades del grupo anarquista territoriano estaba ubicado en la franja nordeste del Territorio Nacional de La Pampa. Comprendía un abanico de poblaciones incipientes y un centro urbano mayor, General Pico. Allí se constituyó el núcleo del movimiento anarquista de la región, que puso en circulación el emprendimiento editorial La Pampa Libre-Pampa Libre (1922-1930). Jorge Etchenique, Pampa Libre, anarquistas en la pampa argentina. (Santa Rosa, Amerindia 2000), 23-26.

${ }^{27}$ Luis Alberto Romero. "Sociedades barriales", 40.

${ }^{28}$ En una coyuntura de fragmentación de las fuerzas a nivel nacional. Las disidencias se evidenciaban entre los sectores del radicalismo que postulaban la abstención electoral, que después pasaron a conformar FORJA, y aquellos militantes que propiciaban la participación en los comicios de 1935. Alejandro Cattaruzza, Historia de la Argentina 1916-1955. (Buenos Aires, Siglo XXI: 2016), 124-125. 
de la centralidad de este tipo de instituciones como una práctica relevante en la sociabilidad territoriana para poder difundir el ideario de una población recién llegada, con escaso nivel de alfabetización, que consideraba a las prácticas de la lectura y escritura como vectores principales de integración y ascenso social.

De esta manera, miradas en su conjunto, las bibliotecas mostraban inicios y características diversas. Si bien algunas fueron fundadas a partir de la militancia política y sus redes en la prensa periódica, muchos de esos centros se transformaron después en bibliotecas populares, que al ser reconocidos por la CPBP comenzaron a recibir aportes y bibliografía. Ello les permitía mayores recursos, al tiempo que les demandaba una apertura y la apoliticidad declamada en el ámbito de los estatutos, como requisitos impuestos desde la Comisión. Diferentes posicionamientos políticos confluyeron con la necesidad que experimentaban grupos mayoritarios de la población que tenían entre sus horizontes de expectativas los ideales de una sociedad moderna ${ }^{29}$ y de un ciudadano ilustrado. En una sociedad en la que la práctica de la lectura y escritura tenía un alto valor, representaba una necesidad inminente en el marco de una sociedad nueva. Estas condiciones generaron una sinergia proclive al advenimiento de numerosas bibliotecas en el este pampeano en las décadas de 1920 y de 1930 (Figura 2).

${ }^{29}$ Adrían Gorelik retoma las categorías de Modernidad y Modernización de Marshall Berman y plantea una combinación entre ambas, una articulación entre los procesos materiales y las representaciones culturales, "La Modernidad entendida como la dialéctica entre la modernización -procesos duros de transformación, económicos, sociales, institucionales- y el modernismo -las visiones y valores por medio de los cuales la cultura intenta comprender y conducir esos procesos-; ..." Adrían Gorelik, "Ciudad, Modernidad y Modernización”, Universitas Humanística, Vol 56, Nº 56 (2003): 14. 
Figura 2. Bibliotecas Populares en el Territorio Nacional de la Pampa (1957)

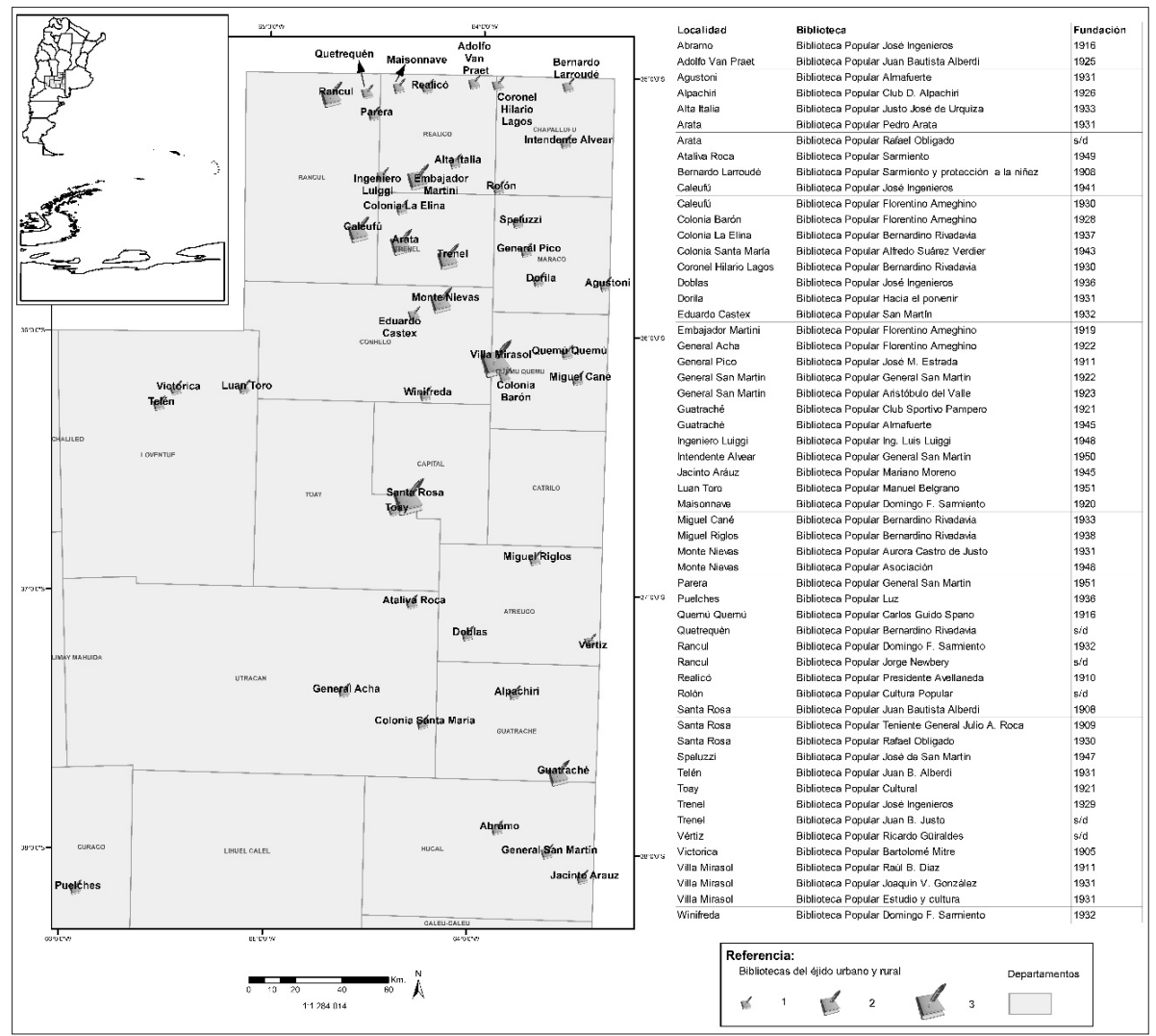

Fuente: Elaboración propia en base a los datos publicados en: Guía de Bibliotecas Públicas de La Pampa. (Santa Rosa: Edición de la Dirección de Cultura, 1957).

La dispersión era una marca significativa en la localización de los establecimientos y respondía a las características de una población distribuida en pequeñas y medianas localidades que dependían del ferrocarril para conectarse con otros centros urbanos. La mayor parte de esas localidades disponía de una biblioteca (ver Anexo 1). Aunque había excepciones, casi todas eran bibliotecas de tercera categoría ${ }^{30}$ con un acervo promedio entre 2000 y 4000 volúmenes, solo ocho establecimientos fueron incluidos en la segunda

30 Según la normativa, correspondían a esta categoría bibliotecas con menos de 4000 volúmenes. 
categoría ${ }^{31}$. La mayor categorización no respondía solamente al requisito legal de la cantidad de volúmenes estipulado por la Ley 419, sino que obedecía también al tipo de actividades desarrolladas por la biblioteca, las condiciones edilicias y las capacidades de gestión de las comisiones directivas.

Además, la cantidad de asociados en relación con otros espacios de sociabilidad de una misma localidad es indicativa de la relevancia de las bibliotecas para los pequeños y medianos centros urbanos. Según los casos examinados en un registro de 1951 que consigna la cantidad de socios, dichas entidades pasaron a ocupar en el Territorio el segundo o tercer lugar, después de asociaciones masivas, como los clubes deportivos. En el Territorio, los clubes más que competir con las bibliotecas, coexistieron con ellas. Si bien en algunos casos se fusionaron con las bibliotecas, en otros, abrieron sus propias bibliotecas o bien prestaron sus instalaciones para que estas pudieran seguir funcionando ${ }^{32}$.

Otra característica distintiva del espacio territoriano fue la presencia de bibliotecas en los espacios rurales, fenómeno que aparece estrechamente articulado con el contexto socio-poblacional y la organización escolar del Territorio $^{33}$. Algunas de esas bibliotecas tuvieron un amplio dinamismo e influencia considerable sobre los espacios urbanos aledaños. Un caso relevante fue el de la Biblioteca Popular San Martín, ubicada en el área rural de la localidad homónima, que llegó a tener dos servicios circulantes en el área urbana.

También es necesario considerar aquí los recursos para el funcionamiento de estas instituciones. En la práctica, los fondos para el sostenimiento de las bibliotecas provenían de la cuota societaria, de los aportes de la CPBP, de subsidios comunales y de las recaudaciones generadas por diversas actividades sociales que llevaban adelante las bibliotecas. La CPBP aportaba el financiamiento de la mitad de las compras de libros solicitados por la comisión

${ }^{31}$ Eran considerados de Segunda categoría aquellas bibliotecas que superaban los 4000 ejemplares.

32 Son los casos de Biblioteca Popular Club Deportivo Alpachiri, Biblioteca Popular José Ingenieros de Caleufú, que funcionaba en el Club Gobernador Centeno, la Biblioteca Popular Bernardino Rivadavia de Coronel Hilario Lagos, que funcionaba en el Club Aguas Buenas, la Biblioteca Popular Almafuerte que dependía del Club Atlético Huracán de Guatraché y la Biblioteca Popular Club Sportivo Pampero de la misma localidad, en Santa Rosa la Biblioteca Rafael Obligado funcionaba en el Club Estudiantes.

${ }^{33}$ Las bibliotecas en áreas rurales o semirurales se corresponden con las localidades de Colonia La Elina, Abramo, Agustoni, Dorila, Speluzzi (lote 3), Villa Mirasol y General San Martin (lote 17). 
directiva. En general, la inversión era decidida en forma consensuada por las distintas comisiones.

Los recursos siempre eran escasos; en 1957, después de una veintena de años de la creación, solamente seis de las 51 bibliotecas populares mencionadas en la Guía de Bibliotecas Públicas - organizada por la Dirección de Cultura provincial- disponían de edificios propios $^{34}$. La mayoría funcionaba en lugares alquilados, en instalaciones cedidas en los clubes, en escuelas y en algunos casos excepcionales, en las sociedades étnicas.

El capital más valorado de esas bibliotecas eran los libros, a ellos se le sumaba el amueblamiento mínimo indispensable para el funcionamiento: una mesa de lectura, sillas, armarios, estanterías, luminarias, entre otros elementos. Los recursos exiguos hacían que muchas de las bibliotecas no pudieran contar con un bibliotecario rentado y la posibilidad de abrir con horario extendido. La atención al público estaba concentrada en unas pocas horas en el turno vespertino para facilitar el acceso de los adultos una vez terminada su jornada laboral.

Cabe destacar que en el contexto pampeano, la actividad de las bibliotecas no se reducía a los préstamos y las prácticas de la lectura, en muchos casos las bibliotecas funcionaban como un espacio de sociabilidad que ofrecía distintas actividades de esparcimiento. En sus épocas de mayor actividad las bibliotecas fueron las encargadas de organizar concursos literarios y artísticos, actos patrióticos, torneos de ajedrez, sorteos, cuadros filodramáticos, conferencias y proyecciones cinematográficas.

\section{Las bibliotecas populares y sus relaciones con las agencias estatales}

Fue durante el primer gobierno de Yrigoyen cuando se aprobó un decreto que funcionó como marco normativo que fijaba atribuciones y facultades de la CPBP ${ }^{35}$. En el Territorio Nacional de la Pampa, a partir de 1918, la Comisión, además de gestionar subsidios, impulsó la creación de nuevas bibliotecas populares en catorce localidades. Los lineamientos formales para gestionarlas denotaban pautas asociativas que eran rémoras de formas y prácticas oligárquicas. La Comisión solicitó al gobernador una nómina de vecinos notables entre los que debían figurar las autoridades municipales, los médicos, farmacéuticos y comerciantes más importantes. Sin embargo, la

${ }^{34}$ Eran las bibliotecas de Victorica, Toay, Winifreda, Realicó, Eduardo Castex e Ingeniero Luiggi.

${ }^{35}$ Fiorucci. "La cultura, el libro", 545. 
convocatoria no tuvo demasiado eco. Ello se puede adjudicar a una estructura de poder endeble y a una falta de organización de la burocracia nacional.

Las bibliotecas que surgieron respondieron a distintas necesidades de la sociedad civil y si bien algunas comisiones captaron los recursos esporádicos del gobierno nacional, en la práctica dichas comisiones se organizaron de manera ecléctica, sin ajustarse demasiado a las recomendaciones del organismo nacional. Como ya se ha advertido, en el Territorio fueron actores centrales en este movimiento los sectores medios y trabajadores. En la gestión de las bibliotecas los maestros, los trabajadores nucleados en asociaciones gremiales, los miembros de agrupaciones políticas, fueron los principales impulsores de las comisiones entre los años veinte y treinta.

Recién en la década de 1930, la gobernación territoriana comenzó a interesarse por mantener algunos registros de las bibliotecas y de otras entidades de la sociedad civil. Las bibliotecas aparecieron referenciadas en la Memoria del gobernador Virasoro en 1935, allí se contabilizaban 76 establecimientos; en tanto que en la Memoria de 1936 - 1937 solo 28 de esas unidades aparecen subvencionadas por insuficientes partidas trimestrales enviadas por el gobierno nacional.

Durante los primeros gobiernos peronistas se aprecia a nivel nacional una expansión del movimiento de creación de estas entidades, el aumento de las partidas presupuestarias y la inclusión de un centenar de nuevas entidades que fueron reconocidas por la Comisión ${ }^{36}$. En La Pampa, la Comisión incorpora la asistencia a 12 bibliotecas. A excepción de la Biblioteca Clemente Andrada y la Biblioteca de Municipal de Intendente Alvear, el resto de las entidades reconocidas en ese periodo, se correspondían con establecimientos ubicados en pequeñas localidades del interior provincial y se incluyó también en la nómina a una biblioteca ubicada en el oeste ${ }^{37}$. Asimismo se ha observado en ese periodo que la CPBP brindaba su aval a algunas bibliotecas, mientras que otras parecieron quedar relegadas.

Durante el peronismo se produjeron cambios normativos a nivel nacional que enfatizaron en la operatividad de las tareas de inspección de las bibliotecas ${ }^{38}$. En el plano local se ensayaron algunos mecanismos de control de la gobernación

${ }^{36}$ Flavia Fiorucci. "La cultura, el libro", 547-548.

${ }^{37}$ La Biblioteca Popular Luz de Puelches, localidad organizada a partir de una de las colonias indígenas.

${ }^{38}$ Los jefes de reparticiones estatales y directivos de establecimientos escolares locales fueron reconocidos como autoridades de inspección. Fiorucci. “La cultura, el libro”, 547. 
"Difundir cultura e ilustración". Las bibliotecas populares en la trama de la sociabilidad de las ... María de los Ángeles Lanzillotta - Micaela Oviedo

sobre las asociaciones, de los que las bibliotecas no permanecieron ajenas. Algunos registros esporádicos elaborados por la policía dan cuenta de informes sobre esos espacios que incluían desde datos cuantitativos sobre su funcionamiento hasta la filiación política de los integrantes de las comisiones directivas $^{39}$, a los que deben añadirse directivas esporádicas que involucraban a determinados dirigentes de algunas entidades, declaradamente contrarios al gobierno de turno.

La Comisión, según lo analizado por Flavia Fiorrucci, no tuvo una política centralizada de adquisiciones, ni de difusión de la lectura ${ }^{40}$. La CPBP continuó con su rol como el agente encargado de comprar los libros seleccionados por las distintas entidades y también, en ocasiones, de encuadernarlos y acondicionarlos para un uso freceunte. Los aportes en dinero para la compra de libros alcanzaban el $50 \%$ de los materiales adquiridos por las instituciones locales, la otra mitad era aportada por las entidades de base.

En las bibliotecas, no hemos encontrado evidencias de políticas concretas vinculadas con el control de lecturas o de donaciones directas de determinados materiales o catálogos ofrecidos por la Comisión hasta los inicios de la década de 1940. En ese sentido, el accionar de las agencias estatales parece haber tenido más intensidad en algunas instituciones que en otras. En la Biblioteca Clemente Andrada de Santa Rosa, ligada a la Escuela Normal ${ }^{41}$ se ha registrado entre fines de los cuarenta y principios de los cinquenta, el ingreso de publicaciones vinculadas a la difusión de la doctrina peronista entre estudiantes y maestros ${ }^{42}$; textos producidos por Juan Domingo y Eva Perón junto con bibliografía que describía los programas de gobierno, como los libros La Argentina de Perón de Ángeles Palacios y Perón 1895-1942, de Enrique Pereyra. En el caso de la Biblioteca Popular "Florentino Ameghino" de Guatraché, se asentaron ocho préstamos de La razón de mi vida solamente durante el año 1952. No obstante,

${ }^{39}$ En 1951 los informes de las asociaciones, generalmente, estaban a cargo de la policía. De 19 asociaciones que fueron informadas, la mayoría de socios figuran como peronistas y sus comisiones se indican como peronistas, a excepción de una. El informe nos permite visualizar los límites a controles que podía ejercer el estado provincial. Fondo de Gobierno. Listado de Asociaciones Provincia Eva Perón. Archivo Histórico Provincial Fernando Aráoz (AHPFA).

${ }^{40}$ Flavia Fiorucci. "La cultura, el libro", 547-551.

${ }^{41}$ Micaela Oviedo, "Las lecturas en las bibliotecas populares pampeanas: el caso de la Biblioteca Popular Clemente José Andrada (1946-1969)". Ponencia presentada en XVI Jornadas Interescuelas, Mar del Plata, 9, 10,11 de agosto, 2017.

${ }^{42}$ Información sustraída del Libro de donaciones y adquisiciones, Biblioteca Clemente José Andrada, Santa Rosa, La Pampa, 1949-1966. 
allí el movimiento en relación con ese tipo de lecturas se concentró en un año puntual y en la obra antes mencionada, pero no tuvo continuidad en el tiempo.

\section{Las bibliotecas populares en la trama de sociabilidad de las ciudades intermedias}

La reducción de escala en este caso nos permitirá analizar con más detalle el funcionamiento de la biblioteca en el marco del microcosmos cultural de las localidades del interior pampeano. Indagaremos en el recorrido institucional de la Biblioteca Popular Florentino Ameghino, organizada en 1921 en Guatraché, una de las localidades intermedias del sudeste territoriano, distante 176 km de Santa Rosa y 189 de Bahía Blanca. La biblioteca surgió cuando habían transcurrido tan solo trece años de la fundación de esa localidad ${ }^{43}$. La agrupación que le dio origen fue la "Sociedad Empleados de Comercio y Anexos en General de Guatraché”, entidad que aunaba a diferentes gremios de la zona con escasa especialización ${ }^{44}$. La Biblioteca fundada el 11 de julio de 1920 tenía entre sus propósitos:
[...]han constituido esta "Sociedad Empleados de Comercio y Anexos en General de Guatraché”, cuyos propósitos son a la vez, estrechar los vínculos de compañerismo, el mejoramiento de sus aptitudes, su elevación cultural y moral y practicar el mutualismo entre sus asociados; y como objetivo principal la fundación de una Biblioteca de carácter Popular.
Considerando que una iniciativa de esta naturaleza, abierta a todas las creencias; sin tendencias ni imposiciones dogmáticas de ninguna especie, y cuya base principal es la de difundir la cultura e ilustración mediante la fundación de una biblioteca, que llenara una necesidad sentida a muchos en la localidad, no dudamos a de merecer la aprobación y apoyo de todas las personas progresistas ${ }^{45}$.

De esa primera etapa, bajo la dependencia gremial, no ha perdurado una documentación institucional específica, a excepción de un libro copiador de la

${ }^{43}$ Guatraché fue fundada en 1908 y para 1914 contaba con 1850 habitantes, para llegar a los 2674 habitantes, en 1947. Además de los nativos, la población inmigrante acusaba de orígenes étnicos diversos, entre los que predominaban ruso-alemanes, españoles e italianos. Silvia Novich, "Guatraché, un lugar en el mundo". En Esta antigua tierra que somos. Guatraché, 1908-2008 (Buenos Aires: Miño y Dávila, 2008), 538.

${ }^{44}$ La Asociación tenía asambleas mensuales ordinarias.

${ }^{45}$ Guatraché, julio de 1920, Libro copiador № 3 de la Sociedad Empleados de Comercio y Anexos en General de Guatraché, Ferrocarril Central Pacífico (LCSEC). 
"Difundir cultura e ilustración". Las bibliotecas populares en la trama de la sociabilidad de las ...

María de los Ángeles Lanzillotta - Micaela Oviedo

entidad gremial que nos permite afirmar algunos trazos de la red que operó en la formación de la biblioteca. La entidad fue organizada según los lineamientos del socialista Ángel Giménez y ello da cuenta de un tejido que articulaba los actores locales con la CPBP y las redes del Partido Socialista:

Siendo los propósitos de esta naciente Sociedad, fundar una Biblioteca Popular para la cual, como se podrá suponer contamos con escasez de medios, me permito dirigirme a ustedes, a fines de rogarle nos ilustre con los datos que ustedes con su gran práctica en la cuestión posee sobre la instalación y disposición en forma económica de la Biblioteca.

Repitiéndole nuestras anticipadas gracias por los datos que se servirá suministrarnos, salúdale atentamente. ${ }^{46}$

El nombre de Florentino Ameghino fue recurrente, otras cinco de las bibliotecas fundadas en el Territorio ese período y respondía a un ideario anticlerical y positivista extendido en las redes de militancia socialista y en el imaginario social de la época ${ }^{47}$.

Bajo esa orientación política los artífices de ese primer grupo conformado por un profesionaly trabajadores de la localidad, se abocaron a la realización de diversas actividades de carácter social, como la formación de una "comisión pro niños pobres de la escuela nacional” y formación de la primera biblioteca popular local. El grupo promovió la organización de obras teatrales y veladas recreativas. Los medios locales destacaban las actividades del cuadro filodramático "Pablo Podestá" que puso en escena comedias que tenían un fuerte componente de crítica social, como Julio Sánchez Gardel, junto a obras de autores reconocidos en las grandes giras de las compañías teatrales, como Alberto Novión. Ese eclecticismo podría ser indicativo de una cierta permeabilidad hacia la cultura de masas como una estrategia cultural promovidas por el grupo ${ }^{48}$, más allá de la centralidad del teatro en la sociabilidad cultural territoriana.

${ }^{46}$ Nota dirigida a Ángel Giménez. Guatraché, Agosto 7 de 1920. LCSEC.

47 Dora Barrancos ha indagado en la importancia de la figura de Ameghino en la militancia socialista en "La escena iluminada", 99. Oscar Terán advierte sobre la relevancia de esta figura en el imaginario social porteño. Véase Oscar Terán, "Vida intelectual en el Buenos Aires fin de siglo 1880-1910”. En Ideas en el siglo. Intelectuales y cultura científica en el siglo XIX latinoamericano, coordinado por Oscar Terán (Buenos Aires: FCE, 2001), 93,

48 Javier Guiamet estudia el caso de las proyecciones promovidas en los centros socialistas en la década del veinte y esboza la idea de permeabilidad hacia la cultura de masas como estrategia del socialismo. De todas maneras, la temática requiere una investigación específica en espacios menos urbanizados. Javier Guiamet, "Prácticas, usos y concepciones en torno 
Pero, a mediados de la década de 1920 se hicieron inminentes transformaciones institucionales que marcaron el porvenir de la biblioteca hasta fusionarse con un club local. La trayectoria institucional pone de manifiesto ciertas similitudes con la perspectiva de Romero, quien en sus estudios para el área de Buenos Aires, advierte un proceso que tuvo como corolario la decadencia de las instituciones más contestatarias en esa década a partir de la consolidación de instituciones cercanas a los grupos de poder estatal y otras entidades de la sociedad civil que fueron debilitando a aquellas organizaciones, focos de resistencia de trabajadores-inmigrantes. No obstante, visto el devenir de la biblioteca de Guatraché, es posible sostener que las posteriores transformaciones institucionales, si bien hicieron que la biblioteca quedara en poco tiempo diligenciada por sectores de poder locales, ello no implicó una inmediata pérdida de relevancia con respecto a otras entidades.

El Centro de Empleados de Comercio de Guatraché a mediados de los años veinte debió declinar sus intentos de transformarse en centro de representación de distintos sectores del mundo del trabajo, al tiempo que otros sectores demostraron un temprano interés por la biblioteca e hicieron rápidas gestiones para que la entidad pasase a la órbita del club "Atlético Pampero". En ese traspaso fue sustancial la intervención del gobierno municipal, conformado como municipio a partir de 1923:

A una solicitud de la Comisión de Empleados de Comercio y Anexos de esta localidad pidiendo un subsidio para la Biblioteca Popular se resuelve indicar a estos modifiquen sus Estatutos en forma liberal, dando el verdadero carácter de popular a la Biblioteca y en caso de hacerlo así esa corporación tratar nuevamente el asunto en oportunidad $[\ldots]^{49}$

Una comisión provisoria de la "Sociedad de empleados de comercio y anexos", el 11 de mayo de 1926, resuelve gestionar el traspaso de los bienes de la biblioteca al "Club Atlético Pampero", entidad de reciente creación. Reciben los bienes socios directivos del club que eran figuras del radicalismo en la comuna local. En ese período la biblioteca comenzó a funcionar en un local alquilado por el municipio, para luego trasladarse a las dependencias del predio del municipal de Guatraché5 ${ }^{50}$, en el año 1927. La biblioteca se mantuvo en las

al cine del partido socialista argentino en la década de 1920", Historia y espacio, n46, (2016): 35-54. doi.org/10.25100/hye.v12i 46.1886

${ }^{49}$ Municipalidad de Guatraché, Acta № 19, 27 de noviembre de 1924.

${ }^{50}$ Municipalidad de Guatraché, Acta № 34, del 7 de junio; №. 43, 6 de abril de 1927. 
instalaciones municipales hasta enero de 1943, momento en el que se organiza en un local independiente.

Mientras se iba acrecentando la participación de amplios segmentos de la población en otros espacios de sociabilidad como los cines-bares, asociaciones étnicas y los clubes ${ }^{51}$, la sociedad local fue depositando en la biblioteca la función cada vez más acotada a la lectura y a la organización de conferencias y veladas literarias sobre temas regionales. No obstante, la comisión, al estar asociada al Club Pampero, se involucró más en la promoción de actividades deportivas, como la organización de carreras de bicicletas, partidos de fútbol, festivales de aviación y otros eventos vinculados con el esparcimiento como la organización de bailes populares y festejos en fechas relevantes para la localidad ${ }^{52}$.

Si bien la institución no contaba con un salón de actos, se valió de otras instituciones para desarrollar una agenda cultural vinculada a un relato identitario pampeano. Algunos de los conferencistas reconocidos que pasaron por ella fueron: Enrique Stieben y Eliseo Tello. Este último dictó dos conferencias, una sobre "La conquista del Desierto", y otra destinada a la descripción del espacio pampeano ${ }^{53}$, mientras que Tello expuso sobre su Toponimia indígena ${ }^{54}$. En el año 1952, la comisión de la biblioteca propició la gestación de un museo regional.

Desde finales de la década del los treinta, el vínculo entre las comisiones de la biblioteca con los sectores de poder local representados por el municipio se hacía cada vez más estrecho. La institución aparece directamente referenciada en el presupuesto municipal desde los albores de los años cuarenta. Se le destinaba una subvención anual exigua, situación que se mantuvo invariable a lo largo de toda la década ${ }^{55}$. A esa partida se le sumaba una subvención de la CPBP, que duplicaba la ayuda del municipio ${ }^{56}$.

${ }^{51}$ Paula Laguarda, "Ambitos de sociabilidad, cine, bailes, romerías y otros entretenimientos populares”. En Esta Antigua tierra que somos Guatraché 1908-2008, editado por Ana María Rodríguez, Marisa Moroni y Oscar Folmer (Buenos Aires: Miño y Dávila, 2008), 314-315.

${ }^{52}$ Libro de Actas N ${ }^{\circ}$. Biblioteca Popular Florentino Ameghino, Guatraché, La Pampa. 19491952.

${ }^{53}$ El Imparcial, № 41, 01-05-1944, № 43, 01-06-1944.

${ }^{54}$ Municipalidad de Guatraché. Res. Nº11, 15- 03-1945.

${ }^{55}$ Municipalidad de Guatraché. Res. № 25, 12-1943, Res. № 1, 1-1-1945, Res. № 11, 1-4-1947, Res. № 166, 15-12-1949, Res. № 34. A partir de 1945 la Biblioteca Almafuerte, recibió el reconocimiento de la CPBP y el doble de subvención municipal, a partir de 1947.

${ }^{56}$ Libro de Actas del Club Pampero. Actas 614-02 -01-1952. 
El giro dado por la institución a lo largo de las dos primeras décadas de vida fue notable. La comisión de la biblioteca, en sus orígenes, perteneció a una agremiación que estaba orientada a nuclear distintos sectores trabajadores pasó a depender de un club, que detentaba estrechas vinculaciones con los sectores políticos representados en el municipio y luego se vio atravesada por los clivajes políticos de la década del cuarenta.

\section{El horizonte de expectativas y las posibilidades de lectoras y lectores}

Más allá del recorrido institucional, nos preguntamos si esos cambios impactaron en las prácticas de la lectura de las/os socias/os que asistían a la biblioteca y si hubo transformaciones a lo largo del período en estudio en relación con las preferencias de ese público lector particular situado en un espacio con escasa urbanización, que se iba conformando distanciado físicamente de los grandes centros intelectuales metropolitanos.

La biblioteca actuaba como facilitadora de los libros para ser prestados a domicilio y para la consulta de periódicos y folletos. Los textos eran seleccionados por los lectores y en este periodo no parece haber mediado una instancia de recomendación de lecturas. A pesar de los cambios institucionales, la biblioteca continuó funcionando hasta 1932 en torno a un grupo de asociados que motu propio registraba préstamos de los libros. A partir de esa fecha contó con una bibliotecaria y abría al público durante dos horas en el turno vespertino. La comisión directiva del club, dejaba en manos de la bibliotecaria gran parte de las actividades, como el pedido de libros, la correspondencia, las memorias, entre otras actividades. Aunque la función principal que cumplía era el registro de los préstamos a domicilio.

El acervo de la biblioteca en sus orígenes era modesto, no alcanzaba los 500 volúmenes, luego llegó a tener -a mediados de los años cuarenta-más de mil de libros, ampliándose considerablemente en los años cinquenta, hasta alcanzar 3.500 volúmenes y más de 1.400 folletos y revistas ${ }^{57}$.

La cantidad de socios estaba cercana a los doscientos para 1930, cuando se llegaron a concretar más de setecientos préstamos anuales. Ahora bien, si se toma en consideración la cantidad de préstamos realizados, la situación es inversa a la disponibilidad de libros. El número de volúmenes se acrecentó desde finales de 1930, mientras que la cantidad de préstamos iba en declive, tendencia que se fue acentuado en la década del cuarenta y que estaba en consonancia también con el proceso de pérdida de población que azotó la

${ }^{57}$ Acta Club Pampero, № 620, 29-03-1953. 
dinámica poblacional de la región, originado en la crisis agroclimática de los años treinta (Figura 3).

Figura 3. Préstamos por año Biblioteca Popular Ameghino. Guatraché

\section{Préstamos por año Biblioteca Popular Ameghino. Guatraché}

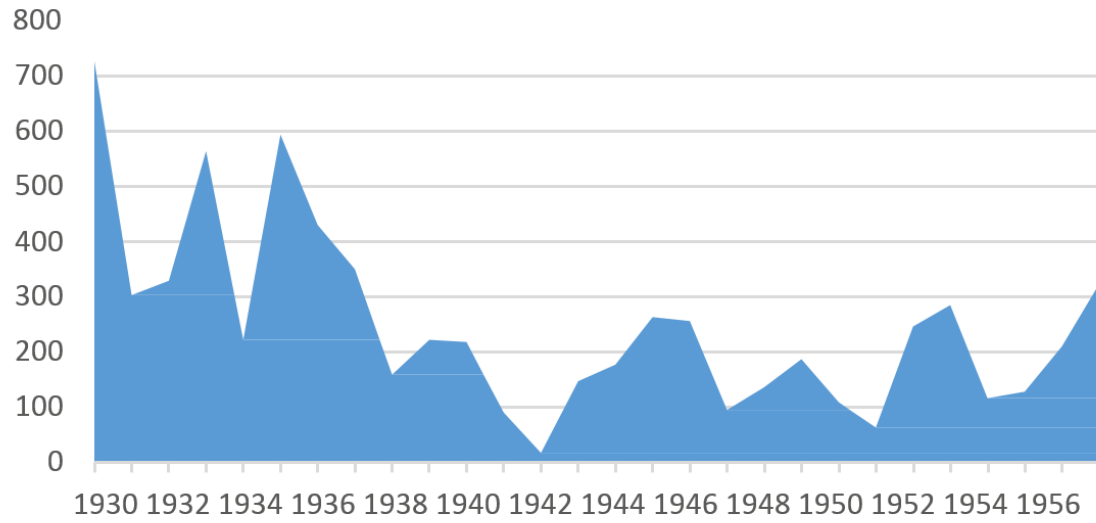

Fuente: Registro de libros llevados a domicilio. Biblioteca Popular Florentino Ameghino. Guatraché. La Pampa.1930- 1958.

En sus inicios la biblioteca se conformó como un espacio al que asistía preferentemente un grupo reducido de varones adultos argentinos y extranjeros, no obstante, a partir de la segunda mitad de la década del treinta, empezaron a tener mayor presencia las mujeres. Solo algunos de los primeros socios eran lectores asiduos ${ }^{58}$, y detentaban militancia social, autodidactas que apostaban a la lectura como principal instrumento formativo.

En cuanto a las preferencias lectoras, se observan cambios y continuidades en todo el período en estudio. Los textos más leídos fueron los de ficción, en esto no se diferencia de otros estudios. Las novelas sentimentales y de aventuras de autores extranjeros y nativos, eran los libros más requeridos. En general, eran textos cortos de ágil lectura, al alcance de las estrategias, habilidades y expectativas de sectores amplios de la población. Como lo ha advertido Ricardo Pasolini para el caso de Tandil ${ }^{59}$, una parte del público lector que asistía a las

${ }^{58}$ Quiroga, "Lectura y política”, 465-466.

${ }^{59}$ Ricardo Pasolini, “Entre la evasión”, 391-392. 
bibliotecas también se sentía atraído por otros textos de carácter naturalista y realista, más comprometidos con realidades sociales duras, como las novelas de Hamsun, France, Tolstoi, Balzac.

Hasta donde nos han permitido las fuentes disponibles en el caso de Guatraché, hemos recorrido la selección de los militantes socialistas, asiduos concurrentes a la biblioteca. Si bien ellos fueron tentados por la ficción más social, entre sus preferencias no estaban ausentes los folletines. Es de destacar que aún entre los lectores más recurrentes con militancia social, gravitaba un corpus de lecturas más comerciales, que dependían de otras mediaciones, por fuera del gremio o del grupo político (Figura 4).

Figura 4. Preferencias por autores años 1920, 1930 y 1952

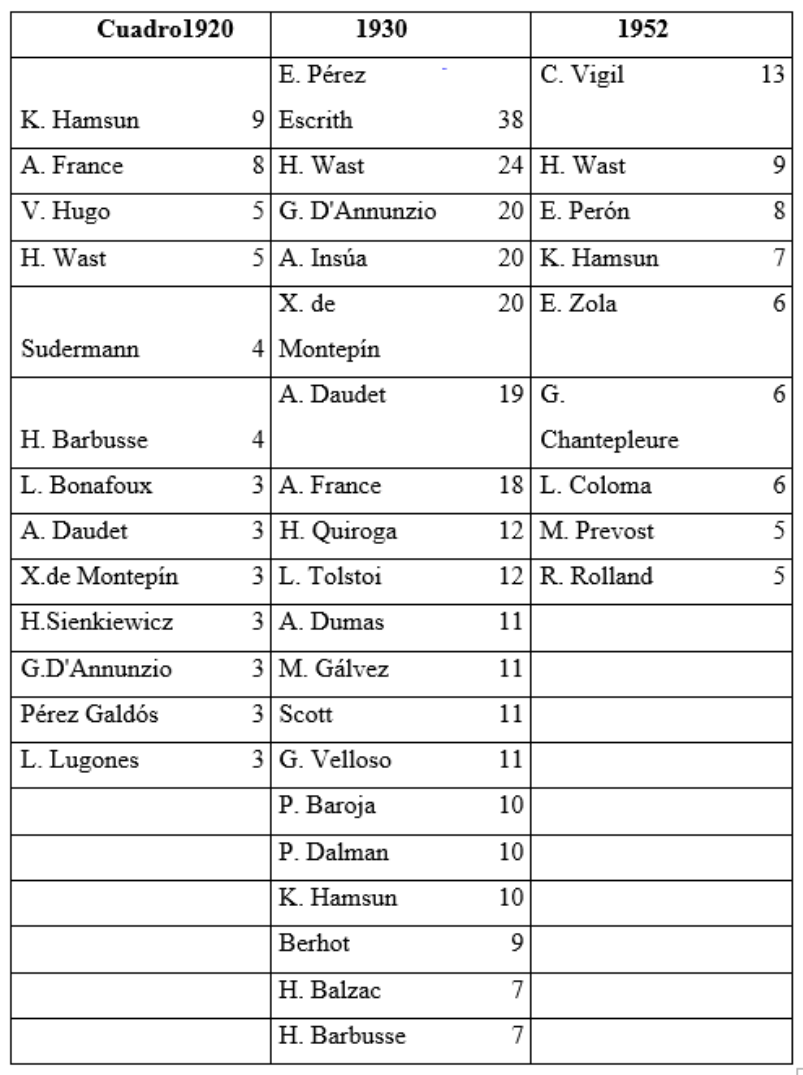

Fuente: La selección de 1920 corresponde al listado de libros solicitados por la comisión gremial a la Comisión Protectora de Bibliotecas Populares. Copiador de Notas. Sociedad de Empleados de Comercio. Los datos de 1930 y 1952 fueron obtenidos a partir del Registro de Libros llevados a domicilio. Biblioteca Popular Florentino Ameghino. Repositorio Club Atlético Pampero. Guatraché. La Pampa. 
El grupo organizador del gremio realizó una primera selección de obras en los años veinte que motivó a profundizar en temas contemporáneos desde una perspectiva crítica. Ese primer corpus estaba compuesto de un abanico de temáticas convocantes que concitaban un interés recurrente: el fantasma de la guerra, el fascismo, la Revolución rusa. Entre las obras requeridas estaban los tomos de El Capital, junto a otros textos de Lenin, Kropotkine, La historia de la Revolución Rusa de Trotsky, entre otros títulos.

A partir de los años treinta otras temáticas, como la integración de los inmigrantes era también motivo de preocupación y ello los acercaba a la selección de nuevas obras, editadas en la Argentina. Las obras de Alberto Gerchunoff eran revisitadas por los lectores del "interior", junto con las de Horacio Quiroga y Hugo Wast. Con respecto a la lectura de este último autor, Nicolás Quiroga, en consonancia con Pasolini, analiza las posibles razones comerciales del éxito que tuvo el autor entre 1928-1931, teniendo en cuenta el gran número de préstamos efectuados entre los lectores novatos, no obstante, es de destacar la permanencia que detentó, excedió el trienio ${ }^{60}$. La narrativa nativista, también tuvo su lugar entre las preferencias del público, aunque parecería haber contado con menos seguidores.

Si bien la biblioteca era en principio un ámbito con preponderancia masculina, algunas de las primeras socias de la institución se convirtieron rápidamente en lectoras y concurrentes asiduas. A diferencia de lo analizado por Romero para las bibliotecas porteñas, a inicios de los años treinta, todavía la asistencia de las mujeres en la biblioteca era una actividad esporádica y en general iban acompañadas de familiares o congéneres de la misma edad. Entre las preferencias femeninas en ese período se observaba una marcada selección en favor de las novelas de origen extranjero, aunque hubo algunas que también incursionaron, con posterioridad, en el ensayo, con la selección de autores como Sarmiento, Matienzo, y Palacios. La situación fue cambiando, hacia la década del cincuenta, cuando el público femenino fue transformándose en mayoritario dentro de la Biblioteca.

Con posterioridad al ingreso masivo de las mujeres y al disponer de un local alquilado de uso específico para la biblioteca, se hizo evidente el crecimiento de la presencia de los niños. Este proceso estuvo acompañando la posibilidad de un trayecto escolar que se extendía a los seis años en la localidad. Algunos de esos jóvenes se convertían en mediadores, leían a pedido de los mayores

${ }^{60}$ Quiroga, “Lectura y política”, 449-474. 
de la familia. Tal como lo evocara entre los recuerdos de su infancia en Toay, un maestro y periodista socialista:

Fui de pequeño un lector de "milicos". Leía para mi padre y para otros, cuando llegaban a mi casa, el diario, los cuentos de Bertoldo, Bertoldino y Cacaseno, las memorias de un vigilante de Fray Mocho, y versos de autores criollos, Hernández, el oriental "Viejo pancho". Escuché relatos reales y ficticios sobre malhechores. ${ }^{61}$

Los diarios, las revistas como Caras y Caretas, Fray Mocho y P.B.T., junto con las representaciones teatrales y el cine resultan claves para explicar las prácticas de lectura entre distintos sectores de la población y aportan elementos significativos a la hora de analizar la difusión de ciertos textos. La prensa, propiciaba la mediación con el mercado editorial desde la década de 1910. A partir de la publicación de escuetos comentarios, los periódicos oficiaban de patrocinadores de las obras, materiales que luego la biblioteca ponía al alcance de los habitantes pueblerinos. Así los nóveles lectores y los ya avezados se acercaban a la secuencia de las colecciones como las de "La cultura argentina" (1915-1925) dirigida por José Ingenieros la “Biblioteca Argentina” de Ricardo Rojas (1915-1928) ${ }^{62}$ o, con posterioridad, la Colección Austral (1937-1970). Estas obras aportaron una parte significativa al corpus de las bibliotecas populares de ese período y perduraron en la década siguiente, ante un público que se renovaba y unos anaqueles que evidenciaron escasas incorporaciones hasta promediar la década del treinta.

A pesar de la participación de la comisiones de la biblioteca en conferencias y actividades vinculadas con la difusión de la historia nacional, los préstamos destinados a publicaciones de esas temáticas fueron de menor cuantía con respecto al peso de la ficción, aunque el interés se vio incrementado a partir de la segunda mitad de la década del treinta. Un primer acercamiento del público lector estuvo orientado a las biografías o a los Episodios Nacionales del Comandante Espora, escritos que tenían una estructura similar a los textos por entregas. Entre los personajes y temas predilectos estaban Juan Manuel de Rosas y Sarmiento, y las polémicas desatadas en torno a esas figuras.

${ }^{61}$ Rodríguez Kessy, De la antigua escuela, 227.

62 Véase Fernando Degiovanni. Los textos de la patria, Nacionalismo, políticas culturales y canon en Argentina. (Buenos Aires, Beatriz Viterbo Editora), 2007. 


\section{Consideraciones finales}

El análisis de conjunto de las distintas bibliotecas populares del Territorio nos muestra la importancia numérica de estas entidades pero también pone en evidencia un abanico de situaciones institucionales que no respondían a un modelo unívoco. El abigarrado mosaico de entidades da cuenta de la presencia que tuvieron las bibliotecas en el contexto de la sociedad civil del este pampeano y nos permite identificar algunos lineamientos recurrentes, como la incidencia que tuvieron las redes de militancias y los emprendimientos culturales de las izquierdas en el surgimiento de estas entidades en la década de veinte, así como el rol de las bibliotecas en la gestación de políticas culturales que impulsaron el proceso de modernización en las sociedades emergentes. A partir de la mediación de las bibliotecas se involucraron en dicho proceso nuevos sectores de la población, aunque sus alcances tuvieron algunas limitaciones, en especial entre la población radicada en áreas más alejadas de los centros urbanos del Territorio; en esos casos la organización de la biblioteca era más dependiente de los maestros, ellos dinamizaron este tipo de emprendimientos en los espacios rurales.

En las décadas del veinte y treinta, las bibliotecas populares diseminadas en la franja nordeste del espacio pampeano se transformaron en agentes de modernización, al incentivar la difusión de pautas culturales y de prácticas sociales al interior de una población escasamente urbana y alfabetizada. Actores que, desde esos ámbitos alejados de los grandes centros de la producción de bienes culturales, tenían la posibilidad de acercase a la biblioteca, que oficiaba como centro cultural, proveedor de esos bienes que resultaban tan preciados, que no incluían solo el acceso a la lectura de periódicos y libros con sus horizontes prometedores, sino que también comprendían la participación en grupos de teatro, juegos, colectas, actos festivos, entre otras actividades.

Las formas organizativas y las prácticas que se desarrollaban en estas entidades fueron luego resignificadas por los agentes de un poder político que en el nivel local se involucró rápidamente con esas nóveles entidades. Más allá de esas primeras décadas, nos debemos aún un estudio específico que nos permita ahondar en las transformaciones operadas en las bibliotecas y en las prácticas de lecturas en el marco de políticas culturales de la gobernación y los circuitos del mercado editorial a partir de los años caurenta.

Diferentes perfiles de lectores participaron de las actividades de la única biblioteca de la localidad hasta 1945. Aún en el caso de los lectores y las lectoras asiduos, la cantidad de obras leída por persona se vio disminuida a partir de 
finales de los años treinta, al tiempo que otras instituciones y otros medios, como el cine y la radio experimentaban un notable crecimiento ${ }^{63}$ en las arenas locales. En todo el periodo en estudio, los textos más revisitados fueron las novelas extranjeras y, en segundo lugar, las nacionales, esas adquisiciones muestran ciertos matices diferenciales con otras realidades cercanas y un despliegue de los circuitos de una industria editorial que en forma temprana se fue expandiendo hacia los distintos centros urbanos del país.

\section{Referencias bibliográficas}

\section{Fuentes Primarias}

\section{Manuscritas}

"Yo", Pedro Fernández Acevedo. Diario personal del maestro y abogado Pedro Fernández Acevedo. (Inédito). Repositorio personal de Esmilda Fernández Acevedo. Santa Rosa, La Pampa.

Copiador de Notas $\mathrm{N}^{\circ} 3$, Sociedad de Empleados de Comercio y Anexos en General, Guatraché, FCP. 1920-1924. Repositorio Club Atlético Pampero de Guatraché.

Fondo de Gobierno. Listado de Asociaciones Provincia Eva Perón. (AHPFA), Santa Rosa.

Libros de Actas Municipalidad del Concejo Municipal de Guatraché (1923-1967). Municipalidad de Guatraché.

Registro de libros llevados a domicilio. Biblioteca Popular Florentino Ameghino. Guatraché. La Pampa.1930- 1958.

Libros de Actas del Club El Pampero. Repositorio Club Atlético Pampero de Guatraché.

Libro de donaciones y adquisiciones. Biblioteca Clemente José Andrada, Santa Rosa, La Pampa, 1949-1966. Santa Rosa.

\section{Editas}

República Argentina, Tercer Censo Nacional de 1914. Población. T. III Buenos Aires, Talleres Gráficos L.J. Rosso. 262-272.

El Imparcial. Periódico. Guatraché, 1940-1947.

Comisión Protectora de Bibliotecas Populares: Nómina de las Bibliotecas Populares que fomenta la Comisión protectora de Bibliotecas Populares, Buenos Aires 1929, Nómina de las Bibliotecas Protegidas, Buenos Aires, 1935; Nómina de las Bibliotecas Protegidas, Buenos Aires, 1938; Nómina de las Bibliotecas Populares Protegidas 1941; Guía de las Bibliotecas Argentinas. T II Buenos Aires, 1955; Nómina de las Bibliotecas Protegidas, Buenos Aires, 1966. Biblioteca Nacional, Buenos Aires.

${ }^{63}$ Paula Laguarda ha analizado la expansión del cine y la radio en el Territorio y advierte de la existencia de cinco cines en la localidad de Guatraché entre 1940-1942, “Ámbitos de sociabilidad", 315 . 
"Difundir cultura e ilustración". Las bibliotecas populares en la trama de la sociabilidad de las ...

María de los Ángeles Lanzillotta - Micaela Oviedo

Guia de Bibliotecas Públicas de La Pampa. Santa Rosa, Edición de la Dirección de Cultura, 1957. Archivo Histórico Provincial Fernando Aráoz.

\section{Fuentes secundarias}

Alonso, Fabio. El peronismo en La Pampa. Conformación partidaria y construcción estatal 1945-1955. Rosario: Prohistoria, 2015.

Barrancos, Dora. La escena iluminada. Ciencias para trabajadores 1890-1930. Buenos Aires: Plus Ultra, 1996.

Billorou, María José y Laura Sánchez. "Escuelas, maestros, inspectores. La dinámica del sistema educativo en el Territorio de la Pampa, 1880-1930”. En Historia de La Pampa: sociedad, política y economía. De los poblamientos iniciales hasta la provincialización, editado por Claudia Salomón Tarquini y Andrea Lluch. Santa Rosa: EdUNLPam, 2014.

Boholavsky, Ernesto. "Sobre los límites del control social. Estado, historia y política en la periferia argentina (1890-1930)". En Instituciones y formas de construcción social en América Latina, 1840-1940, una revisión, editado por María Silvia Di Liscia y Ernesto Boholavsky. Buenos Aires: Prometeo, 2005.

Carli, Sandra. "Infancia y Sociedad. La mediación de asociaciones, centros y sociedades populares de educación". En Historia de la Educación en la Argentina. Sociedad civil y Estado en los orígenes del sistema educativo argentino, dirigido por Adriana Puiggrós. Buenos Aires, Galerna, 1998.

Cattaruzza, Alejandro Historia de la Argentina 1916-1955. Buenos Aires: Siglo XXI, 2016.

Degiovanni, Fernando. Los textos de la patria, Nacionalismo, políticas culturales y canon en Argentina. Buenos Aires: Beatriz Viterbo Editora, 2007.

Di Liscia, María Silvia y Andra Lluch, "La población pampeana y sus transformaciones". En Historia de La Pampa, sociedad política yeconomía, desde los poblamientos iniciales hasta la provincialización (ca.8000 ap. a 1952), editado por Andrea Lluch y Claudia Salomón Tarquini. Rosario: Ediciones del Boulevard, 2008.

Di Liscia, María Silvia. "Dificultades y desvelos de un estado interventor. Instituciones, salud y sociedad en el interior argentino. La Pampa, 1930-1946", Anuario IEHS, n ${ }^{\circ} 22$, (2007): 93-123.

Etchenique, Jorge. Pampa Libre, anarquistas en la pampa argentina. Santa Rosa, Amerindia, 2000.

Fiorucci, Flavia. "La cultura, el libro y la lectura bajo el peronismo: el caso de la Comisión de Bibliotecas Populares". Desarrollo económico- Revista de Ciencias Sociales, 48, nº 192, Enero-Marzo (2009): 543-556.

Folco, María Esther y María Lanzillotta, "El Radicalismo". En Historia de La Pampa, sociedad política y economía, desde los poblamientos iniciales hasta la provincialización (ca.8000 ap.a 1952), editado por Andrea Lluch y Claudia Salomón Tarquini, 395405. Rosario: Ediciones del Boulevard, 2008.

Gorelik, Adrían “Ciudad, Modernidad y Modernización”, Universitas Humanística, 56, vol. 56, (2003): 11-28. 
Guiamet, Javier. “Prácticas, usos y concepciones en torno al cine del partido socialista argentino en la década de 1920”. Historia y espacio, n²46, (2016): 35-54. doi. org/10.25100/hye.v12i46.1886

Guiamet, Javier. “Tentaciones y prevenciones frente a la cultura de masas. Los socialistas argentinos en el periodo de entreguerras”. Tesis de Doctorado en Historia. Universidad Nacional de La Plata. Defendida en septiembre de 2017 [inédita].

Laguarda, Paula. "Ámbitos de sociabilidad: cines, bailes romerías y otros entretenimientos populares". En Esta Antigua tierra que somos Guatraché 1908-2008, editado por Ana María Rodríguez, Marisa Moroni y Oscar Folmer. Buenos Aires: Miño y Dávila, 2008.

Lanzillotta, María de los Ángeles. "De lectores y anaqueles: Bibliotecas Populares”. En Esta Antigua tierra que somos Guatraché 1908-2008, editado por por Ana María Rodríguez, Marisa Moroni y Oscar Folmer, 329-338. Buenos Aires: Miño y Dávila, 2008.

Leloutre, Susana. “Las bibliotecas populares entre los años 1998-2003." Tesis de Licenciatura, Universidad Nacional de La Plata, 2010.

Martocci, Federico. La política cultural del Partido Socialista en el Territorio Nacional de La Pampa: dispositivos y prácticas de intervención de sus dirigentes e intelectuales, 1913-1939. Santa Rosa: EDULPam, 2015.

Novic, Silvia. “Guatraché, un lugar en el mundo”. En: Esta antigua tierra que somos. Guatraché, 1908-2008, 535-550. Buenos Aires: Miño y Dávila, 2008.

Oviedo, Micaela. "Las lecturas en las bibliotecas populares pampeanas: el caso de la Biblioteca Popular Clemente José Andrada (1946-1969)”. Ponencia presentada en XVI Jornadas Interescuelas, Mar del Plata, 9, 10, 11 de agosto, 2017.

Parada, Alejandro. El dédalo y su ovillo ensayos sobre la palpitante cultura impresa en la Argentina. Buenos Aires: Facultad de Filosofía y Letras Universidad de Buenos Aires, 2012.

Pasolini, Ricardo. "Entre la evasión y el humanismo. Lecturas, lectores y cultura de los sectores populares: La Biblioteca Juan B. Justo de Tandil, 1928-1945“.Anuario del IEHS, 12 (1997): 373-401.

Planas, Javier. Libros, lectores y sociabilidades de lectura. Una historia de los orígenes de las bibliotecas populares en la Argentina. Buenos Aires: Ampersand, 2017.

Prislei, Leticia. "Imaginar la Nación, modelar el desierto: los '20 en tierras del Neuquén”. En Pasiones sureñas. Prensa y cultura política en la Frontera Norpatagónica (1884-1946), editado por Leticia Prislei. Buenos Aires: Prometeo, 2001.

Quiroga, Nicolás. "Lectura y política. Los lectores de la Biblioteca Popular Juventud Moderna de Mar del Plata (fines de los años treinta y principios de los cuarenta)". Anuario del IESH, 18 (2003), 449-474.

Rodríguez Kessy, Cristóbal Cleto. De la antigua escuela y otras historias. Buenos Aires: Imprenta de los Buenos Ayres, 2006.

Romero, Luis Alberto. "Los sectores populares en la ciudades latinoamericanas del siglo XIX: la cuestión de la identidad”, Desarrollo Económico Revista de Ciencias Sociales, 27, n⿳ำ 106 (1987): 201-222. 
Romero, Luis Alberto y Leandro Gutiérrez. "Sociedades barriales, bibliotecas populares y cultura de los sectores populares: Buenos Aires, 1920-1945”. Desarrollo Económico Revista de Ciencias Sociales, 29, n 113, (1989): 35-62.

Tedesco, Juan Carlos y Alejandra Cardini. "Educación y sociedad, proyectos educativos". En Una historia social del siglo XX, T.II compilado por Susana Torrado. Buenos Aires: Edhasa, 2007.

Terán, Oscar. “Vida intelectual en el Buenos Aires fin de siglo 1880-1910”. En Ideas en el siglo Intelectuales y cultura científica en el siglo XX latinoamericano, Oscar Terán (coord.) Buenos Aires: Fondo de Cultura Económica, 2001.

Valencia, Luciano. "El Partido Socialista". En Historia de La Pampa, sociedad política y economía, desde los poblamientos iniciales hasta la provincialización (ca.8000 ap. a 1952), editado por Andrea Lluch y Claudia Salomón Tarquini, 415-425. Rosario: Ediciones del Boulevard, 2008. 


\section{Anexo 1}

Tabla. Bibliotecas Populares en La Pampa: volúmenes y préstamos

\begin{tabular}{|c|c|c|c|c|}
\hline Localidad & Biblioteca & Categoría & Volúmenes & Préstamos \\
\hline Santa Rosa & $\begin{array}{l}\text { Biblioteca Popular Juan Bautista } \\
\text { Alberdi }\end{array}$ & Segunda & 11515 & 11315 \\
\hline Realicó & $\begin{array}{l}\text { Biblioteca Popular Presidente } \\
\text { Avellaneda }\end{array}$ & Tercera & 8137 & 6547 \\
\hline Victorica & $\begin{array}{l}\text { Biblioteca Popular Bartolomé } \\
\text { Mitre }\end{array}$ & Segunda & 6855 & 1200 \\
\hline General Pico & $\begin{array}{l}\text { Biblioteca Popular José M. } \\
\text { Estrada }\end{array}$ & Segunda & 6133 & 2055 \\
\hline $\begin{array}{l}\text { Gra l. S a n } \\
\text { Martín }\end{array}$ & $\begin{array}{l}\text { Biblioteca Popular General San } \\
\text { Martín }\end{array}$ & Tercera & 4910 & 1328 \\
\hline Villa Mirasol & Biblioteca Popular Raúl B. Díaz & Tercera & 4500 & 1050 \\
\hline $\begin{array}{l}\text { Gra l. S a n } \\
\text { Martín }\end{array}$ & Biblioteca Aristóbulo del Valle & Segunda & $s / d$ & $\mathrm{~S} / \mathrm{d}$ \\
\hline Toay & Biblioteca Popular Cultural & Segunda & 4287 & 250 \\
\hline Guatraché & $\begin{array}{l}\text { Biblioteca Pop. Club Sportivo } \\
\text { Pampero [1] }\end{array}$ & Tercera & 4000 & 2400 \\
\hline Winifreda & $\begin{array}{l}\text { Biblioteca Popular Domingo F. } \\
\text { Sarmiento }\end{array}$ & Tercera & 3000 & 718 \\
\hline Dorila & $\begin{array}{l}\text { Biblioteca Polular "Hacia el } \\
\text { porvenir" }\end{array}$ & Escolar & 2859 & 1338 \\
\hline $\begin{array}{l}\text { E d u a r d o } \\
\text { Castex }\end{array}$ & Biblioteca Popular San Martín & Tercera & 2698 & 3372 \\
\hline Guatraché & Biblioteca Popular Almafuerte & Tercera & 2600 & 2400 \\
\hline Arata & Biblioteca Popular "Pedro Arata" & Escolar & 2310 & 1600 \\
\hline General Acha & $\begin{array}{l}\text { Biblioteca Popular Florentino } \\
\text { Ameghino }\end{array}$ & Tercera & 2274 & 800 \\
\hline Santa Rosa & $\begin{array}{l}\text { Biblioteca Teniente General Julio } \\
\text { A. Roca }\end{array}$ & Segunda & $\mathrm{s} / \mathrm{d}$ & $S / d$ \\
\hline $\begin{array}{l}\text { In g e n i e r o } \\
\text { Luiggi }\end{array}$ & $\begin{array}{l}\text { Biblioteca Popular Municipal } \\
\text { Ing. Luiggi }\end{array}$ & Segunda & $\mathrm{s} / \mathrm{d}$ & $\mathrm{S} / \mathrm{d}$ \\
\hline $\begin{array}{l}\text { In g e n i e r o } \\
\text { Luiggi }\end{array}$ & $\begin{array}{l}\text { Biblioteca Popular Ing. Luis } \\
\text { Luiggi }\end{array}$ & Tercera & 2235 & 1000 \\
\hline $\begin{array}{l}\text { Adolfo Van } \\
\text { Praet }\end{array}$ & $\begin{array}{l}\text { Biblioteca PopularJuan Bautista } \\
\text { Alberdi }\end{array}$ & Tercera & 2009 & 248 \\
\hline Alpachiri & $\begin{array}{l}\text { Biblioteca Popular Club D. } \\
\text { Alpachiri }\end{array}$ & Tercera & 2000 & 1650 \\
\hline
\end{tabular}


"Difundir cultura e ilustración". Las bibliotecas populares en la trama de la sociabilidad de las ... María de los Ángeles Lanzillotta - Micaela Oviedo

\begin{tabular}{|c|c|c|c|c|}
\hline QuemúQuemú & $\begin{array}{l}\text { Biblioteca Popular Carlos Guido } \\
\text { Spano }\end{array}$ & Tercera & 2000 & 750 \\
\hline E. Martini & Biblioteca Florentino Ameghino & Tercera & 1893 & 294 \\
\hline Jacinto Aráuz & $\begin{array}{l}\text { Biblioteca Popular Mariano } \\
\text { Moreno }\end{array}$ & Tercera & 1750 & 2400 \\
\hline Bdo. Larroudé & Biblioteca Popular Sarmiento & Tercera & 1750 & 600 \\
\hline Monte Nievas & $\begin{array}{l}\text { Biblioteca Popular Aurora Castro } \\
\text { de Justo }\end{array}$ & Tercera & 1575 & 500 \\
\hline Trenel & $\begin{array}{l}\text { Biblioteca Popular José } \\
\text { Ingenieros }\end{array}$ & Tercera & 1564 & 5250 \\
\hline Simson & $\begin{array}{l}\text { Biblioteca Popular Domingo F. } \\
\text { Sarmiento }\end{array}$ & Tercera & 1350 & 2190 \\
\hline Doblas & $\begin{array}{l}\text { Biblioteca Popular José } \\
\text { Ingenieros }\end{array}$ & Tercera & 1350 & 540 \\
\hline Villa Mirasol & Biblioteca Popular Raúl B. Díaz. & Segunda & s/d & $\mathrm{S} / \mathrm{d}$ \\
\hline Villa Mirasol & $\begin{array}{l}\text { Biblioteca Popular Joaquín V. } \\
\text { González }\end{array}$ & Escolar & 1320 & 100 \\
\hline Santa Rosa & $\begin{array}{l}\text { Biblioteca Popular Rafael } \\
\text { Obligado }\end{array}$ & Tercera & 1267 & 200 \\
\hline Rancul & $\begin{array}{l}\text { Biblioteca Popular Domingo F. } \\
\text { Sarmiento }\end{array}$ & Tercera & 1183 & 571 \\
\hline Caleufú & $\begin{array}{l}\text { Biblioteca Popular José } \\
\text { Ingenieros }\end{array}$ & Tercera & 1175 & 1500 \\
\hline Monte Nievas & Biblioteca Popular Asociación & Tercera & 1136 & 1312 \\
\hline Caleufú & $\begin{array}{l}\text { Biblioteca Popular Florentino } \\
\text { Ameghino }\end{array}$ & Escolar & 1020 & 900 \\
\hline Luan Toro & $\begin{array}{l}\text { Biblioteca Popular Manuel } \\
\text { Belgrano }\end{array}$ & Tercera & 1012 & 650 \\
\hline Hilario Lagos & $\begin{array}{l}\text { Biblioteca Popular Bernardino } \\
\text { Rivadavia }\end{array}$ & Tercera & 980 & 260 \\
\hline Miguel Cané & $\begin{array}{l}\text { Biblioteca Popular Bernardino } \\
\text { Rivadavia }\end{array}$ & Tercera & 900 & 300 \\
\hline Speluzzi & Biblioteca José de San Martín & Tercera & 884 & 800 \\
\hline Trenel & Biblioteca Popular Juan B. Justo & Tercera & 854 & S/d \\
\hline Telén & Biblioteca Juan B. Alberdi & Escolar & 802 & 250 \\
\hline Agustoni & Almafuerte & Escolar & 800 & 120 \\
\hline Alta Italia & $\begin{array}{l}\text { Biblioteca Popular Justo José de } \\
\text { Urquiza }\end{array}$ & Tercera & 788 & 200 \\
\hline $\begin{array}{l}\text { Colonia La } \\
\text { Elina }\end{array}$ & $\begin{array}{l}\text { Biblioteca Popular Bernardino } \\
\text { Rivadavia }\end{array}$ & Escolar & 758 & 480 \\
\hline
\end{tabular}




\begin{tabular}{|l|l|c|c|c|}
\hline Colonia Barón & $\begin{array}{l}\text { Biblioteca Popular Florentino } \\
\text { Ameghino }\end{array}$ & Escolar & 680 & 1500 \\
\hline Ataliva Roca & Biblioteca Popular Sarmiento & Escolar & 640 & 220 \\
\hline $\begin{array}{l}\text { In ten d e n t e } \\
\text { Alvear }\end{array}$ & $\begin{array}{l}\text { Biblioteca Popular General San } \\
\text { Martín }\end{array}$ & Tercera & 620 & S/d \\
\hline Villa Mirasol & $\begin{array}{l}\text { Biblioteca Popular Estudio y } \\
\text { cultura }\end{array}$ & Escolar & 614 & 96 \\
\hline $\begin{array}{l}\text { Colonia Santa } \\
\text { María }\end{array}$ & $\begin{array}{l}\text { Biblioteca Popular Alfredo } \\
\text { Suárez Verdier }\end{array}$ & Escolar & 505 & 785 \\
\hline Parera & $\begin{array}{l}\text { Biblioteca Popular General San } \\
\text { Martin }\end{array}$ & Tercera & 491 & S/d \\
\hline Miguel Riglos & $\begin{array}{l}\text { Biblioteca Popular Bernardino } \\
\text { Rivadavia }\end{array}$ & Tercera & 468 & 469 \\
\hline Puelches & Biblioteca Popular Luz & Escolar & 400 & 69 \\
\hline Abramo & José Ingenieros & Escolar & 210 & 100 \\
\hline
\end{tabular}

Fuente: Guía de Bibliotecas Públicas de La Pampa. Santa Rosa, Edición de la Dirección de Cultura, 1957. 